\title{
Preguntas pendientes a la Descentralización: ¿Está conduciendo hacia la igualdad de género?
}

Rebeca Centeno*

* Investigadora y docente del Programa de Género de la Universidad Centroamericana (UCA), Apdo. 69, Managua, Nicaragua. E-mail: rebeca@ns.uca.edu.ni

Recibido: septiembre de 2006 / Aceptado: octubre de 2006

LA AUTORA DEL ARTÍCULO INDAGA EN LA DIMENSIÓN POLÍTICA DE LA Descentralización, estableciendo vínculos con el orden social de género. Indica que, a pesar que históricamente las mujeres han estado vinculadas con los servicios municipales y participan activamente en organizaciones locales, éstas no son ciudadanas plenas, a juzgar por la manera en que participan en instancias de decisión: a medida que aumenta el poder, disminuye su participación. Argumenta que están infrarrepresentadas en los cargos de alcaldes (as), y carecen del principio de individualidad (principal característica de los miembros de la polis).

Estos elementos guardan relación con las preguntas políticas pendientes a la Descentralización. Son interrogantes que cuestionan la naturaleza del municipio y del gobierno local: no por ser más cercanos a la población son más democráticos.

Deigualforma,paralaautora,la Descentralizaciónseconstituyeenunaoportunidad para la ciudadanía femenina. Las institucionalidades locales emergentes deben de asumir el principio de igualdad, de lo contrario, el protagonismo de las mujeres se verá invisibilizado -como de antaño- en concepciones teóricas-metodológicas de carácter androcéntrico que han marcado el desarrollo en general y el local en particular.

Palabras clave: Descentralización administrativa / gobierno local / igualdad / género (sexo) / mujeres-participación ciudadana

\section{Introducción}

La Descentralización remite a las reformas políticas y administrativas que transfieren competencias, funciones y recursos a niveles inferiores del Estado y cercanas a la 
población. Este proceso estuvo marcado en América Latina en la década de los años ochenta, por imperativos de modernización y eficiencia, provenientes de la corriente neoliberal.

Distintos estudios mencionan que el proceso de Descentralización en Nicaragua no surgió de demandas de los niveles intermedio y local, sino al contrario, fue un proceso inductivo: ha sido dinamizado e impulsado desde el gobierno central hacia las localidades.

El diagnóstico de CINCO (Centro de Investigaciones de la Comunicación) en 2003, sobre la Descentralización en Nicaragua, señala las debilidades teóricas y conceptuales de la racionalidad que ha orientado el proceso de Descentralización en nuestro país: "La Descentralización al igual que el proceso de reforma del Estado hasta ahora, han sido operados a partir de enfoques eminentemente técnicos que han apuntado a una reingeniería institucional en la búsqueda de la disminución, eficiencia y eficacia del aparato de gobierno" (Montenegro y Cuadra, 2003: 16).

Montenegro y Cuadra manifiestan que el enfoque y el tipo de Descentralización que se ha empujado no se enmarcan en la democratización del Estado, sino en la eficiencia administrativa y la adecuación de las estructuras institucionales para insertarse a los procesos económicos de la globalización. Este proceso ha generado la búsqueda de un modelo de desarrollo local de "baja intensidad", donde la participación de los actores a este nivel, tiene la función de asegurar un mínimo de gobernabilidad en situaciones de pobreza, exclusión y conflicto. Se ubica el avance de la Descentralización todavía en la etapa de desconcentración administrativa ${ }^{1}$.

A pesar del enfoque y del tipo de Descentralización que se desarrolla en Nicaragua, también la Descentralización y la reforma del Estado deberían visualizarse por todos los actores, especialmente los del sistema político, como una oportunidad inigualable para replantearse un nuevo modelo de relaciones entre el Estado y la sociedad nicaragüenses. Estos procesos están más allá de la función estrictamente administrativa, sino que apuntan a un objetivo político nacional: la consolidación democrática del Estado nicaragüense (Montenegro y Cuadra, 2003).

La Descentralización para los municipios de Nicaragua, ha significado múltiples retos. Por un lado los esfuerzos para lograr una efectiva Descentralización (administrativa y política) y por otro, los desafíos relativos a la construcción de la Democracia: la participación ciudadana, la protección de los derechos humanos, la confianza en las instituciones y la creación de mecanismos de inclusión social.

Así también, en el escenario local se experimentan cambios en las relaciones del Estado con la ciudadanía, lo que se denomina el núcleo de la gobernabilidad. Se promueve la conciencia ciudadana, las personas asumen identidades socio- territoriales y exigen a los gobiernos locales que desarrollen capacidades para conducir procesos -en conjunto con los actores sociales- hacia el desarrollo y la creación o fortalecimiento de instituciones que le dan forma a la Democracia.

En los municipios nicaragüenses existen actores sociales que, a través de formas 
institucionalizadas, participan en la planificación estratégica de su municipio y luchan por colocar en agenda pública sus intereses, convirtiéndose en ciudadanos activos e interlocutores con el Estado. Las mujeres, a pesar de su creciente participación, todavía no ostentan la categoría de ciudadanas debido a dos elementos relacionados entre sí; el primero remite a la falta de individualidad (principal característica de los miembros de la polis), y el segundo a la manera en que participan del poder en el ámbito local. Estos elementos guardan relación con las preguntas políticas pendientes a la Descentralización. Son interrogantes que cuestionan su propia naturaleza: no por ser el gobierno local y el municipio más cercanos a la población son más democráticos.

La Descentralización en Nicaragua ha sido estudiada más en su dimensión técnica (génesis, avances y dificultades) que en su dimensión política. Las preguntas políticas tienen que ver con la dinámica del poder, aspecto que muy poco se ha constituido en objeto de investigación.

Los discursos atingentes a la equidad de género y a la igualdad de oportunidades que proliferan en el marco de la Descentralización, de cierta forma crean condiciones para que este proceso se constituya en una oportunidad para el empoderamiento femenino, sobre todo si tomamos en cuenta los compromisos asumidos por los gobiernos para lograr los Objetivos de Desarrollo del milenio ${ }^{2}$. Estos objetivos paradójicamente han sido tildados como “ciegos al género" (Kabeer, 2003; Murguialday, 2006), a pesar que uno de los 8 objetivos literalmente enuncia: "Promover la igualdad de género y empoderar a las mujeres". No obstante, aglutinan un amplio consenso y movilización social y representan una oportunidad para la ciudadanía femenina.

Las ideas de este escrito se desarrollan en torno a la tensión omnipresente entre ciudadanía y género ${ }^{4}$. Utilizaré categorías analíticas de las Ciencias Sociales en general y de la teoría de género en particular. El género concebido como una estructura, es posible utilizarlo en su vertiente analítica, es decir, desentrañar las relaciones de poder que subyacen en los mecanismos formales e informales de participación ciudadana e identificar las desigualdades sociales y formas inexplícitas de exclusión social. Es de singular importancia conocer los determinantes de la participación política de las mujeres en el contexto local, ya que si en estos procesos no se crean mecanismos para que éstas participen en condiciones de igualdad que los hombres en su municipio, sus intereses serán definidos por grupos de poder y subsumidos -como de antaño- en lo que se defina como prioritario. Se trata por tanto de aspectos que guardan relación con la construcción de la democracia.

\section{Las mujeres en el poder político local}

En la literatura sobre desarrollo local y Descentralización se menciona que el perfil del gobierno local en Latinoamérica se enrumba hacia la Gobernabilidad Democrática. Al respecto, Massolo (2005) explica que la gobernabilidad se refiere a un conjunto de condiciones del sistema político que juegan de mediación entre la sociedad y el Estado. Pudiendo existir tres tipos de gobernabilidad: la dictatorial, la autoritaria y la democrática. Argumenta Massolo que el componente esencial de la Gobernabilidad Democrática es la legitimidad, la cual se fundamenta en la legalidad política, el respeto a los derechos, en la 
capacidad, eficacia y rendimiento de los actores responsables del ejercicio del poder público que logran el apoyo y credibilidad de parte de la ciudadanía.

Para la autora antes mencionada, existen dos condiciones para que la Gobernabilidad democrática local logre sus objetivos: la autonomía del gobierno local y la participación ciudadana. En este sentido Nicaragua ha logrado importantes avances en materia jurídica: la Constitución de la República de Nicaragua, la Ley de Municipios y sus reformas del 26 de Agosto de 1997, y la Ley 475, Ley de Participación Ciudadana, entre otros. En este marco jurídico encontramos la filosofía referida a la autonomía municipal, la participación ciudadana como medio y fin de la democracia, así como mecanismos e instancias de participación.

En el marco de la Descentralización, se han institucionalizado espacios de participación ciudadana: cabildos, referendos, comités de desarrollo municipal y departamental, y mesas de concertación. Se observa en algunas localidades una importante densidad institucional, en la que organismos de la sociedad civil, organizaciones de base, asociaciones de mujeres y sectores productivos demandan sus derechos individuales y colectivos.

En las instancias de participación ciudadana, institucionalizadas a nivel local, las mujeres participan activamente. Ellas históricamente - más que los hombres- han estado familiarizadas con los servicios que prestan los gobiernos locales, dado sus roles reproductivos, considerados como "naturales" desde la construcción social de género. En contextos de pobreza como el nicaragüense, son ellas -como proyecto vital- quienes se esfuerzan para mejorar la calidad de vida de sus familias y sus comunidades.

Las mujeres, explica Massolo (2005), no sólo han garantizado la sobrevivencia familiar, sino también en contextos de pobreza y crisis económica, han contribuido y contribuyen a mantener la gobernabilidad local logrando resolver carencias que se sufren en la vida cotidiana, mediante la tenaz intermediación ante las autoridades locales, las luchas populares y organizaciones comunitarias. Gracias a los enormes esfuerzos y desgastes de las mujeres de sectores populares y fracciones de la clase media, las políticas de ajuste neoliberal y las crisis económicas no han provocado crisis generalizadas de ingobernabilidad en los espacios locales de América Latina ${ }^{5}$.

A pesar del aporte de las mujeres a la gobernabilidad, en el escenario local nicaragüense encontramos una paradoja: inclusión / exclusión social. Las mujeres aparecen en calidad de representantes de un Organismo no Gubernamental, de una institución del Estado, de una organización comunitaria, en las instancias de participación ciudadana (mesas de concertación, comisiones y en los Comités de Desarrollo Municipal). Sin embargo, la democracia representativa no se expresa en la realidad, pues están infrarrepresentadas en el poder político: las mujeres apenas constituyen el 10\% en los cargos de alcaldes (as) y el $11.5 \%$ en los de vicealcaldes (as). Se evidencia, entonces, la tendencia de la participación femenina en el poder político: a medida que aumenta el poder de decisión, disminuye la participación de las mujeres. 


\section{Desigualdad en instancias de participación ciudadana y en estructuras directivas}

Actualmente todos los municipios de Nicaragua están desarrollando procesos de planificación. El nivel de desarrollo es disímil, como disímil son sus capacidades y recursos. La mayoría ha formulado su plan de desarrollo municipal y todos se orientan bajo las directrices emanadas del Sistema de Planificación municipal del INIFOM. Dicho sistema contempla como eje transversal la equidad social, de género, étnica y cultural. Define como instancias de participación ciudadana a los CDM (Comités de Desarrollo Municipal), Comités territoriales y mesas / comisiones de trabajo.

La Red Nicaragüense para la Democracia y el Desarrollo Local realizó, en el año 2006, un diagnóstico sobre la situación de los $\mathrm{CDM}^{6}$. Una de las características generales es que están conformados por gobernantes municipales (alcaldes o vice alcaldes y concejales), personas delegadas de instituciones del Estado en los municipios (MINSA, MECD, MAGFOR, MARENA, IDR), líderes territoriales, representantes de organismos no gubernamentales, iglesia católica y evangélica, representantes de la empresa privada, gremios, asociación de jóvenes y asociaciones de mujeres.

De igual forma, en el año 2004 se realizó un Diagnóstico sobre Género y Desarrollo Local. Sus resultados nos permiten analizar la participación ciudadana tomando en cuenta la división genérica de la sociedad. Encontramos que del total de personas que participan en los CDM, el 60.7\% son hombres y el 39.3\% son mujeres, y representan a diversos sectores e instituciones (BID-INIFOM, 2004)

La participación de las mujeres en los CDM varía según la naturaleza del área / institución, siendo mayor en las de carácter social: Educación (70.6\%) y Salud (46.4\%). En las instituciones de carácter productivo disminuye la participación de las mujeres, son el 35.2\% de las personas delegadas del MARENA, el 20.4\% de la representación del MAGFOR y el $3.4 \%$ del IDR. Son el $25.8 \%$ de las personas que representan a la Policía Nacional y el (5\%) de las delegadas por el Ministerio de Gobernación (BID-INIFOM, 2004).

La presencia de mujeres como representantes de instituciones del Estado no necesariamente es un indicador de avance en la igualdad de género. Si la institución a la que representan no ha asumido el enfoque de género, las mujeres figurarán entonces para salvaguardar los intereses de su organización (técnicos, económicos en general).

En los datos señalados se evidencia la existencia de un fenómeno denominado segregación ocupacional en sus dos expresiones: horizontal y vertical. La primera se manifiesta en que las mujeres se concentran en un determinado número de profesiones o áreas (las del área social, con menos valor social y con menos recursos).

La segunda-segregación horizontal-se expresa cuando las mujeres se sitúan en los escalones más bajos en las estructuras laborales y tienen una escasa presencia en puestos de élite (Amorós, 2000). Encontramos que las mujeres son minoría (22.2\%) dentro de las estructuras técnicas y administrativas de las municipalidades / alcaldías. Están subrepresentadas en los cargos de dirección en las municipalidades (22\%), a pesar de que ellas representan el 
37.8\% del personal técnico y profesional, según datos del Diagnóstico de género y desarrollo municipal del año 2004.

La segregación vertical y horizontal son evidencias de la división sexual del trabajo fundamento del sistema patriarcal- y se trata del reparto social de tareas en función del sexo. Es una construcción social que, anclada en fundamentos de orden biológico, establece mayor valor social a lo considerado "masculino", es decir, tareas, funciones, atributos "propios de los hombres", y asigna subalternidad a lo considerado "femenino".

También se identifica el fenómeno de "El techo de cristal", el cual es definido como una barrera invisible pero infranqueable, que no permite acceder a las mujeres a los puestos de dirección. En ese sentido, Amelia Valcárcel (1997) en "La Política de las mujeres", tematiza sobre los argumentos esgrimidos para alejar a las mujeres del poder. Indica que mediante la ideología Patriarcal se arguye que las mujeres no ostentan el poder porque carecen de la formación necesaria. Valcárcel argumenta que en este nuevo siglo, en el mundo occidental, las cifras indican la sobrecalificación de las mujeres con respecto a los hombres. En nuestro contexto existe paridad genérica en el sistema educativo y las mujeres son mayoría en el ámbito universitario. Como vemos, las desigualdades producidas por el Patriarcado carecen de fundamento.

Elámbito del trabajo se caracteriza por la precariedad de los puestos de trabajo, la flexibilidad de los contratos y la desregulación laboral, que son signos de la Globalización. Distintos estudios demuestran que las mujeres son las más perjudicadas ${ }^{7}$. Estas características se evidencian en las Alcaldías en los contratos laborales analizados por sexo: las mujeres como asesoras son minoría (32.9\%) y es un trabajo de forma permanente. En el puesto de consultor (a), las mujeres constituyen el (59.6\%), se trata de ocupaciones ocasionales de mayor desregulación laboral. (INFOM - FISE, 2004)

La Ley de Municipios y la Ley de Participación Ciudadana mandatan a constituir instancias de participación, las cuales se contemplan en el Sistema de Planificación municipal. Las Mesas de concertación / Comisiones de trabajo se organizan según los temas considerados estratégicos y pueden ser: ambiental, municipal, salud, educación, niñez, mujer, juventud, economía, seguridad ciudadana y auditoría social, (Castillo 2006). En estas instancias las mujeres representan el 49\% de las personas participantes (INIFOM-BID, 2004).

Los CT (Comités territoriales) son instancias de planificación municipal. En éstos las mujeres representan el 36.2\%. Por área geográfica, las mujeres urbanas participan más que las rurales (41.2\% y 36.6\%) respectivamente. En calidad de líderes de su comunidad, una de cada tres personas que participan en los CT son mujeres (33.4\%); la participación de las mujeres urbanas -como líderes- es mayor que las rurales (33.1\% en Comités urbanos y 21\% en Comités rurales) (INIFOM-BID, 2004).

Como se observa, en las instancias de toma de decisiones y de planificación (CDM y CT), la participación de las mujeres es menor en relación a los hombres. En cambio, en las instancias de consulta y de concertación (Mesas / Comisiones de trabajo) se incrementa la participación de las mujeres a un grado paritario. 
Estos resultados invitan a plantearnos algunas interrogantes: ¿La participación de las mujeres es utilitaria? ¿Por qué se observa paridad en instancias de consulta y no así en las de mayor poder de decisión? ¿Existe posibilidad de que los intereses de las mujeres figuren en la agenda local? ¿Qué tipo de ciudadanía ostentan las mujeres? ¿Estaremos ante la presencia de lo que Evangelina García (2006) denomina el Espejismo de la Igualdad?

La ciudadanía femenina en sus vínculos con el desarrollo ha sido vigorosamente criticada: se ha interpelado los enfoques y puesto en entredicho sus objetivos ${ }^{8}$. En el marco de la Descentralización, también surgen resquemores. Cos Montiel (2006: 10) sostiene que "en algunos casos, detrás de los discursos de Descentralización, es evidente el uso instrumental de las mujeres. La literatura general está llena de ejemplos donde la participación de las mujeres se limita a poco más que el suministro de tiempo y esfuerzos para iniciativas que tienen que ver con el logro de objetivos deseables de desarrollo”.

Los datos antes señalados reflejan la desigualdad de las mujeres en el ámbito político. Desentrañar las estructuras y mecanismos que la perpetúan es una asignatura pendiente. Retomarlos como objeto de investigación permitirá conocer la calidad de nuestra democracia. Por ello, el vínculo entre democracia y género en el marco de la Descentralización, requiere de estudios a profundidad en los cuales se conceptualice al género como un ordenador social (Connell, 1987), como un campo desde donde se articula el poder (Scott, 1990), y como una estructura anclada en las instituciones (Goetz, 1995; Caber, 1998).

\section{4. ¿La Descentralización promueve la ciudadanía de las mujeres?}

En el escenario local se encuentran organizaciones / instituciones que se les denomina Actor(es) social (es). Realizar un mapeo de éstos es parte consustancial a todo proyecto local. La categoría actor social remite, desde la perspectiva Weberiana, a la acción basada en el sujeto. Para Weber (citado en Calhoun et. Al., 2000) los hechos sociales no son otra cosa que el resultado acumulativo de las acciones sociales de los individuos.

Actor social es parte del léxico municipal y nacional, y crea dificultad tanto en su dimensión semántica como política. Desde la dimensión semántica se nombra a las mujeres como "actrices" o "actoras". Palabras que no responden al significado e implicaciones políticas del concepto sociológico.

La búsqueda del nombre "actor social" en femenino, es parte de los esfuerzos de visualizar el protagonismo de las mujeres, dada la exclusión e invisibilización de la que han sido objeto. La lengua de carácter sexista ensombrece a las mujeres cuando concibe a los sustantivos plurales masculinos como genéricos universales. Desde su dimensión política, el término actor social se refiere a grupos que han logrado poner en agenda pública sus intereses, es decir, son ciudadanos activos de la polis local. Las mujeres no son parte de estos grupos.

La ciudadanía es pertenecer a una comunidad política, sobre la base de derechos y deberes civiles, políticos, sociales, culturales y económicos, formalmente atribuidos (García, 2003). Para efectos analíticos se debe distinguir entre ciudadanía activa y ciudadanía pasiva. La primera, es el derecho a decidir sobre los arreglos sociales de la comunidad política de 
pertenencia; es el ejercicio efectivo de los derechos, las personas son consideradas miembros de la polis. La segunda, es la posibilidad de acceder a derechos políticos, económicos y sociales, pero la definición de los derechos y la posibilidad del acceso a éstos, la realizan quienes ejercen el poder político.

A juzgar por las formas de participación femenina, la Descentralización no ha traído consigo la ciudadanía activa de las mujeres. Se desconoce de la existencia de agendas de género en los municipios; esto es lograr que los problemas e intereses de las mujeres sean objeto de política pública. Existen desigualdades como la violencia contra las mujeres y niñas (expresiones del Patriarcado global), que reúnen esfuerzos mundiales para su prevención y erradicación, sin embargo, no son parte de las prioridades locales. Se desconoce de casos en donde las mujeres hayan logrado convocar al $\mathrm{CDM}^{9}$ para este problema de salud pública y de desarrollo.

\subsection{Las mujeres: "las idénticas”, "las indiferenciadas”.}

En la literatura sobre el municipalismo en general y el desarrollo local en particular (reglamentos de ley de municipios, Ley de Participación Ciudadana, visión en los planes estratégicos municipales), se alude al tema de género y/o de la mujer. Se desprende una lectura en la cual género es sinónimo de mujer y éstas -las mujeres- son homologadas como un sector social, al igual que la niñez, la adolescencia y la tercera edad. Las mujeres figuran como "las idénticas" en relación a "los individuos" (hombres) que en argumentos de Celia Amorós (1985), reviste consecuencias para el ejercicio de la ciudadanía. Para las primeras, la falta de autonomía: principal característica de los miembros de la polis; para los segundos: el principio de la individuación, es decir, "titulares” de derechos.

Amorós realiza un análisis crítico a planteamientos teóricos que sustentan y legitiman la inferioridad de las mujeres -y su incapacidad para ejercer el poder- al asociar conceptualmente a éstas a la naturaleza y a los hombres a la cultura. En este sentido expresa que, al conceptuar a las mujeres como naturaleza, se las excluye de la individualidad. Los varones son conceptualizados por la ideología patriarcal como individuos por ser creadores de la cultura ${ }^{10}$ y capaces de elevarse a la abstracción. En cambio, lo femenino es tematizado por el patriarcado como una masa inseparable e incapaz de producir individualidades.

El término "mujer" incide en la carencia de la ciudadanía activa, ya que hace suponer que todas las mujeres -como masa inseparable- tienen idénticos intereses. En otras palabras, a las mujeres no se les identifica a partir de otros roles que no sean los domésticos, por ello sus intereses son subsumidos en los intereses de la familia. En la realidad local y nacional encontramos mujeres productoras, en los partidos políticos, al frente de empresas del sector privado, mujeres estudiantes, trabajadoras del sector público, obreras de maquilas etc. La realización de diferentes actividades en el ámbito público marca la diversidad de sus intereses. En cambio, a los hombres se les representa como individuos, como titulares de derechos, se les diferencia, a partir de sus roles productivos. Por ello cabe la interrogante: ¿Las mujeres son concebidas entonces como seres vulnerables objetos de asistencia por parte del Estado o como actores activos del desarrollo? 
También dicha homologación parece ignorar que el género es una categoría social que se intersecta con otros ejes de desigualdad como son la clase y la etnia. Es decir, la exclusión social de las mujeres no deviene únicamente del sistema de orden sociocultural (Patriarcado) sino también de la coexistencia de éste con el sistema socioeconómico (Neoliberalismo). Precisa entender que la exclusión histórica de las mujeres a los recursos del desarrollo y al poder en general, se explica también por su pertenencia a grupos de igual forma excluidos: pobres, indígenas, no heterosexuales, analfabetas, rurales, de una religión o partido político no hegemónico.

La escasa presencia de mujeres en el poder político también se explica por la división entre lo público y lo privado $^{11}$. El ámbito público / político es un espacio que a las mujeres les es ajeno, porque se ha configurado mediante el paradigma masculino. Mediante las formas de hacer política (Cultura Política), se observan en nuestro país, estilos verticales, centralistas y caudillistas, que hacen que las mujeres no se identifiquen con el poder. La frase elocuente de J. Astelarra (1990) nos lo explica: "No hay que preguntarse qué les pasa a las mujeres que no les gusta la política, sino: ¿Qué tiene la política que no les gusta a las mujeres?”.

El camino a la gobernabilidad democrática requiere de la identificación de la diversidad de individuos y la pluralidad de sus intereses. Demanda del reconocimiento de individuos con igual poder de definir las políticas públicas, de exigir la protección de sus derechos humanos y de erradicar los mecanismos que los (las) excluyen. No tomar en cuenta estos principios afecta la legitimación del Estado.

Por otro lado, la eficiencia y la efectividad requieren de tener en consideración el conjunto heterogéneo de actores económicos demandantes de servicios y recursos, y a la vez contribuyentes al crecimiento económico y al desarrollo. Posiblemente un gobierno que realmente otorga prioridad a estos paradigmas, sin sesgos de género, es más apto para reconocer y considerar a las mujeres como actores económicos que un gobierno benefactor con su énfasis en lo social y su percepción predominante de las mujeres como grupo vulnerable (Backhaus, 2002).

Las estadísticas desagregadas por sexo y la capacitación sobre el tema de Género son factores básicos en todo esfuerzo que se encamine a lograr la Igualdad. En ese sentido, El Diagnóstico de Género y Desarrollo Municipal (2004) revela dos grandes debilidades: Concluye que la mayoría de las municipalidades no cuenta con estadísticas actualizadas y, las existentes, no están desagregadas por sexo, área geográfica, grupos etéreos y etnia. Se menciona además, la falta de formación en género de la mayoría de los gobernantes municipales y de los equipos técnicos de planificación.

Alejandra Massolo (2002) describe que términos como perspectiva de género, igualdad de oportunidades, equidad de género, ciudadanía de las mujeres, entre otros, son parte de la innovación conceptual de la gestión municipal y han adquirido carta de ciudadanía en Latinoamérica. En Nicaragua resulta común encontrar estas expresiones desde el quehacer de Organismos no gubernamentales, algunas instituciones del Estado y en las municipalidades. Sin embargo, la aplicación de estos conceptos requiere ser objeto de estudio, ya que, por un lado, pueden ser contrarios a los objetivos deseados de equidad 
- dada la forma indistinta y a veces equivocada en el uso de estos términos- y, por otro, dan la idea de que la igualdad de género en el ámbito local ya se ha logrado.

\subsection{La aparente igualdad de género}

La presencia creciente de mujeres en instancias de participación ciudadana nos remite a lo que García (2006) nombra el espejismo de igualdad. Los argumentos de esta autora son elaborados a partir de ciertos signos que denomina "vitales", porque mantienen la idea de la igualdad como un hecho ya alcanzado. García compara su tesis con algunas estudiosas como Marcela Lagarde, quien se ha referido a fenómenos semejantes como "velo de la igualdad", que opera -según García-, como en el caso del famoso "velo de la Ignorancia" referido por John Rawls en su "Teoría de la Justicia”, como un mecanismo ideológico que oculta o impide ver, en este caso, la realidad desigual.

A continuación se utiliza el marco analítico de García (2006) contextualizado a la realidad nicaragüense:

1) La ilusión de igualdad se produce ante la presencia de mujeres en ámbitos en los que no era frecuente verlas (cargos públicos, espacios de toma de decisiones). Es un proceso hacia la Igualdad, pero no es una meta ya alcanzada, dada la inexistencia de paridad en los órganos de poder.

2) La sistemática alusión al tema de la igualdad de género produce el efecto de creer que es un hecho efectivo. La referencia la encontramos en las normativas y conferencias internacionales, en las agendas nacionales e internacionales, promovidas principalmente por el Sistema de Naciones Unidas y UNIFEM. También se alude en las directrices y misión de la Cooperación Internacional.

3) La mención de las mujeres en los discursos políticos y académicos, dan la idea que existe efectivamente un compromiso con la igualdad de género, y que es algo ya logrado.

4) No es común distinguir entre la igualdad que creemos tener y la desigualdad que experimentamos. No siempre hay conciencia de la discriminación. Algunos discursos de mujeres que ejercen poder entrañan una falsa igualdad.

5) Cuando existen mujeres nominalmente representativas (a la cabeza de un espacio directivo) se asocia que en las organizaciones existen compromisos con la igualdad genérica y que ésta es una realidad para todas las mujeres.

6) La fuerte movilización alcanzada por las mujeres en la defensa de sus derechos a escala global, puede llegar a interpretarse como indicador de igualdad real.

7) La difusión en los medios de comunicación global de algunas situaciones puntuales de igualdad aparente, alcanzada por las mujeres, se asume como un hecho globalizado, generalizado y estructural. 
8) Cuando se define el enfoque de género como transversal, "es decir todo y nada a la vez": no siempre se definen las formas de operativizarlo ni se le asignan recursos técnicos y financieros. La transversalización equivocadamente se interpreta como un fin y no como un medio para alcanzar la igualdad.

9) El desconocimiento del enfoque de género -teórico y metodológico- repercute en discursos optimistas, que consideran que la intervención femenina en instancias de participación ciudadana es sinónimo de enfoque de género.

Estos hechos, en su conjunto, podrían estar influyendo en la construcción de representaciones e imaginarios colectivos que conciben que la igualdad entre hombres y mujeres es un hecho real.

\section{Algunos avances en la incorporación del enfoque de género}

La presencia de mujeres en instancias de participación ciudadana es un avance para la democracia local en construcción. Varios son los factores que han influido en ello: "los signos" de la Descentralización que asume como principios inherentes la participación ciudadana y la legitimación de los gobiernos; la beligerante movilización organizada del movimiento de mujeres y del movimiento feminista en sus expresiones a nivel global, nacional y local; la influencia de la Cooperación Internacional, que asume la equidad de género como un medio para alcanzar la Igualdad; los avances en materia jurídica (normas, convenciones, leyes) y los Objetivos de desarrollo del Milenio (uno de los objetivos a cumplir por los gobiernos al año 2015 es "empoderar a las mujeres").

Signados por el principio de no exclusión, encontramos esfuerzos tendientes a revertir las desigualdades de género; en algunas alcaldías existen áreas u oficinas de la mujer: Managua, Estelí, Río San Juan. En aquellas que no tienen áreas específicas, "los asuntos de las mujeres" se abordan en las Oficinas de Participación Ciudadana o en la Dirección de Servicios Municipales.

La mayoría de los municipios nicaragüenses son parte de una forma de cooperación mutua, fenómeno conocido como Asociacionismo o Asociatividad municipal. ${ }^{12} \mathrm{En}$ las asociaciones que tienen mayor desarrollo, el tema de género forma parte de su plan estratégico, se explicita en la visión y misión institucional. La asociación de municipios de Río san Juan se destaca por impulsar dicha temática; han logrado obtener fondos de agencias de cooperación y cuentan con apoyo de organizaciones de mujeres.

En el Diagnóstico Nacional sobre Género en el Desarrollo Municipal (2004), se indagó sobre la incorporación del enfoque de género en el proceso de planificación municipal. Los resultados fueron los siguientes: De los municipios que cuentan con su PDM, ${ }^{13}$ el 59\% incorporan dicho enfoque. Es en el diagnóstico - parte del PDM- donde más se ha incorporado aspectos de género. A nivel de las normativas locales, sólo el 7.8\% de los municipios cuentan con ordenanzas que favorecen a las mujeres.

La incorporación del enfoque de género en los diagnósticos municipales es un avance en 
pro de la igualdad, ya que permite evidenciar brechas de género a nivel local y, por ende, encaminar esfuerzos para revertirlas.

En el Plan de Inversión Municipal Multianual (PIMM) es donde se seleccionan los proyectos a ser ejecutados, se identifican fuentes financieras y se programa su ejecución. Al respecto, la consulta realizada para el Diagnóstico de Género y Desarrollo Municipal 2004, indica que la mayoría de las municipalidades no contempla el enfoque de género en el PIMM. El municipio de Boaco es el que se distingue por realizar esfuerzos en este tema.

En la investigación realizada por Belli y López (2005): "Análisis de la articulación de los instrumentos de planificación municipal y departamental con el Plan nacional de desarrollo", se menciona que en la formulación de los PDD (Planes de Desarrollo Departamental), cinco departamentos especifican montos de inversión, uno de ellos es Río San Juan. Este departamento es el único que define el sector "Género", como sector que demanda la inversión para el período 2004 - 2008.

Como parte de los avances que merecen resaltar, es el realizado en el año 2004 por el INIFOM y el BID. Se trata de un proyecto piloto de dos experiencias de incorporación del enfoque de género en el sistema de planificación municipal (Boaco y Ciudad Sandino), se capacitó al personal técnico de las Alcaldías y se elaboraron manuales para conducir el proceso. De igual forma es importante destacar el proyecto -en ciernes- impulsado por la OEA y AMUNIC de la incorporación del enfoque de género en los presupuestos de 15 municipalidades. También se conoce de experiencias, en el año 2006, de formulación de políticas municipales con enfoque de género en cuatro Alcaldías de Nueva Segovia.

A nivel nacional, existen algunas iniciativas de incorporación del enfoque de género en las instituciones del Estado: la Policía Nacional, el Ministerio del Trabajo, el Sistema Judicial, y ministerios del área rural (MAGFOR, INTA). A pesar que no existen diagnósticos generales que den a conocer el "estado del arte", se conoce de las limitantes que han marcado este proceso ${ }^{14}$ : falta de vínculos entre las políticas de género institucionalizadas entre ministerios y las estrategias de desarrollo; el personal femenino encargado de estas áreas (llevan a cabo otras responsabilidades y figuran como únicas responsables de la definición e implementación de estas políticas) poseen muy limitado poder de decisión y escaso presupuesto para realizar sus funciones. Salvo la experiencia de la Policía Nacional, el resto de instituciones no ha logrado la transversalización de dicho enfoque.

Como se deduce en este apartado, el tema de la Igualdad de género en el quehacer institucional, tanto nacional como local, es de carácter incipiente.

\section{La Descentralización como desafío y oportunidad para el empoderamiento femenino}

Empoderamiento es un proceso mediante el cual las mujeres, individual y colectivamente, toman conciencia de las relaciones de poder que afectan sus vidas. Ganan la autoconfianza y la fuerza necesaria para cambiar las desigualdades de género en el hogar, la comunidad, y en los niveles nacional y local. Incluye componentes cognitivos, psicológicos, políticos y 
económicos, todos ellos relacionados entre sí.

El término empoderamiento es utilizado cuando se tematiza al género como relaciones de poder. Este término es polémico utilizado en castellano y, a la vez, reivindicado por los movimientos feministas, en su afán por explicar la participación de las mujeres en la compleja arena del poder público (Arana y Centeno, 2003).

Para Magdalena León, “el rasgo más sobresaliente del término empoderamiento es contener la palabra poder, de manera que su uso es un llamado de atención sobre las relaciones de poder o del poder como relación social (...) la idea de empoderamiento también se ha relacionado con una nueva noción de poder, basada en relaciones sociales más democráticas y en el impulso del poder compartido" (León, 1997: 13-14).

El vocablo empoderamiento, surgido desde las mujeres feministas del sur, alude a la impronta del feminismo como es la igualdad de género. Es utilizado cuando se analizan contextos de desigualdad y se define además como resultado de propuestas metodológicas emancipadoras de otros sectores subalternos en la sociedad.

Si partimos de que la Descentralización trae consigo la institucionalización de la participación y redistribución del poder, creando con ello las bases para la Gobernabilidad democrática local, cabe plantearse lo siguiente: ¿Los procesos de Descentralización están creando condiciones para el empoderamiento femenino? ¿Las mujeres tienen poder de decisión sobre las políticas públicas que afectarán sus vidas?

Es mucho lo que se espera de la Descentralización democrática, especialmente en sus formas innovadoras. La literatura sobre el tema de la participación ciudadana indica la siguiente expectativa: a medida que el gobierno se acerque más a la gente, habrá más gente participando en las políticas que les aseguren la representación, factor clave del empoderamiento.

Autoras como Britos (2000) y Massolo (2000) argumentan fehacientemente que la Descentralización del Estado es una oportunidad para la reducción de las desigualdades de género. Britos (2000: 8) expone: "Descentralizar significa que se transfieren o delegan gran parte de las actividades que eran atendidas por el Estado central a los gobiernos provinciales y de éstos a su vez a los municipios. Las organizaciones de base local comenzarán a tener mucho peso en las decisiones políticas, y al ser el espacio local el lugar privilegiado para la práctica e iniciativa de las mujeres, éstas tendrán mayor oportunidad de integrarse activamente a la vida comunitaria y al desarrollo local. Resulta fácil concluir que el proceso de Descentralización, si es una medida técnica de valoración positiva, sería un "mainstreaming ${ }^{15}$ " de género a favor del empoderamiento y constitución del sujeto femenino.

Por su parte Alejandra Massolo (2000: 8) exhorta: "El empoderamiento se entiende como un proceso de superación de la desigualdad de género. Lo ideal es que las mujeres logren un empoderamiento del proceso de Descentralización, para que ésta sea entendida como un medio que de ser bien encaminado, puede llegar a ser una herramienta vital en la búsqueda 
de la reducción de la desigualdad de género”.

La Descentralización representa un desafío para los gobiernos locales cuando a ésta se le interroga desde la perspectiva de género, ya que remite justamente al reto sin parangón, como es la construcción de la democracia. Al respecto, García (2003: 1) reflexiona: "Sostener y reforzar los sistemas democráticos en América Latina es hoy un objetivo fundamental, pero ello sólo será plenamente posible si se profundiza en un concepto de ciudadanía que tiene como norte los derechos humanos y donde el reconocimiento de la pluralidad, el respeto a la diversidad y una verdadera igualdad entre hombres y mujeres tengan plena cabida."

También la Descentralización -como todo proyecto en construcción- enfrenta riesgos. Uno de ellos es que puede reforzar la histórica subalternidad femenina al no considerar la doble o triple jornada de las mujeres ${ }^{16}$. En espacios de participación ciudadana, Clara Jusidman (2004) explica que la carga que significa en tiempo y esfuerzo, además de información y conocimientos suficientes, para el desarrollo de las agendas locales, recae crecientemente sobre la espalda de las mujeres. La sobrecarga se produce en razón de la equívoca idea de que las mujeres disponen de mucho tiempo libre dada la persistente desvaloración social y económica de su contribución a la economía del cuidado, es decir, la desconsideración de su contribución al bienestar humano por su trabajo doméstico.

Con distintos énfasis y resultados, en Latinoamérica se desarrollan experiencias de incorporación del enfoque de género en el ámbito local. Alejandra Massolo (2002) muestra ejemplos innovadores: En Colombia la Descentralización ha dado paso a la planeación con perspectiva de género; en Bolivia la ley de participación promueve espacios de acción de políticas públicas, incluidas las de igualdad de género a nivel local; y en Chile, el proceso descentralizador propicia la equidad de género a nivel local. En Centroamérica, se destaca El Salvador por incluir la perspectiva de género dentro de los planes de desarrollo municipal.

Nicaragua tiene mucho que aprender de las experiencias latinoamericanas. El camino que conduce a la Gobernabilidad Democrática, que incorpore el principio de la Igualdad sin reductos, se torna difícil en un contexto en el que no se ha logrado la vigencia de la Ley de Igualdad de derechos y oportunidades para hombres y mujeres. Este vacío jurídico es un indicador de la calidad de nuestra Democracia. No obstante, también nuestro país proporciona ejemplos ${ }^{17}$ valiosos en términos de Igualdad y Ciudadanía.

\section{La rendición de cuentas a las mujeres}

La rendición de cuentas es un tema pocas veces vinculado con el orden social de género. Es una temática polémica, pues justamente cuestiona el poder de individuos, organizaciones e instituciones.

Las mujeres -si son ciudadanas activas- deben de exigir la rendición de cuentas a todos aquellos actores (instituciones, organizaciones, organismos de la sociedad civil, gobiernos locales) que desarrollan una urdimbre de actividades realizadas con el esfuerzo femenino y además reivindican la representación de sus necesidades y/o intereses. 
La rendición de cuentas parte del principio: los que tienen el poder deberían responder ante quienes les han delegado el poder. Deben responder ante ellos en el sentido de explicar y justificar sus acciones (dar cuenta) y deberían recibir penas (esta es la parte de "hacer cumplir' de la rendición de cuentas) si sus acciones se consideran inapropiadas o abusivas" (Goetz citada en Cos Montiel, 2006).

La dimensión de la rendición de cuentas relativa a la eficiencia es la que más ha sido demandada. Manor (citado en Cos Montiel, 2006) sostiene que la rendición de cuentas es "el elemento más crucial en las descentralizaciones exitosas”.

Según los argumentos de eficiencia, un Informe del Banco Mundial (1999) manifiesta que la rendición de cuentas financieras es un factor fundamental del éxito "Cuando un gobierno central mantiene una política creíble en contra de los rescates financieros, obliga a los gobiernos subnacionales y a quienes les hacen préstamos a vivir con las consecuencias de sus decisiones. Tienen que rendir cuentas de lo que piden y de lo que prestan".

La rendición de cuentas no se debe analizar únicamente desde su dimensión técnica, sino también desde su dimensión política. Desde lo técnico se evalúan por ejemplo, los resultados de la gestión municipal en base al presupuesto asignado vía transferencias del presupuesto de la República. El control social de parte de la ciudadanía (dimensión política) debe contemplar además, aquellos elementos intangibles, que guardan relación con el empoderamiento femenino, es decir, remiten a las preguntas políticas pendientes a la Descentralización.

Hoy día es común encontrar en los planes estratégicos de instituciones / organizaciones sociales objetivos referidos a la equidad y/o igualdad de género. Éstas deben demostrar la forma en que se traducen éstos objetivos, no sólo a través de los resultados, sino también explicitando cómo se ha creado condiciones para que las mujeres desarrollen su "agencia".

Se entiende por "Agencia" aquellos procedimientos que centran su atención en el "proceso" es decir, todos aquellos mecanismos que propician la construcción de la ciudadanía femenina. Este enfoque es explicado por Naila Kabeer quien define 3 fases que deben caracterizar los cambios; las elecciones estratégicas de vida pueden pensarse en términos de tres dimensiones o momentos distintos en el proceso de cambio social: recursos (precondiciones), agencia (proceso) y logros (resultados). La agencia tiene que ver con más que sólo la acción observable; también abarca el significado, motivación y propósito que los individuos le aportan a su actividad, su sentido de agencia, o lo que las feministas han llamado "poder interior $^{18 "}$ (Kabeer citada en Cos Montiel, 2006).

Identificar la "Agencia", es un ejercicio que cuestiona la manera en que se desarrollan los proyectos que responden al principio de igualdad de género. Sin embargo, el análisis resultaría incompleto si no indagamos en la "fuente", esto es responder a la pregunta: ¿A quién deben pedir cuentas las mujeres? ¿Quién o quiénes deben ser sometidos al control de las ciudadanas? 
Existen argumentos que sostienen que ya hay suficientes desafíos al pedir la rendición de cuentas dentro de las instituciones del Estado ${ }^{19}$. Sin embargo, si la gestión de los gobiernos locales se encamina a la gobernabilidad democrática, debe rendir cuentas a las mujeres.

La rendición de cuentas tiene fuertes vínculos con el empoderamiento, en una relación de causa y efecto. Por medio de la rendición de cuentas las mujeres se empoderan, pues hacen uso de sus derechos sociales, civiles y políticos, y a la vez es el resultado de que la sociedad las ha percibido como sujetos políticos con la capacidad de pedir cuentas a la comunidad política de la que son parte.

\section{Conclusiones}

La gobernabilidad democrática entendida en términos generales como el equilibrio entre las demandas sociales y la capacidad de respuesta de los gobiernos, exige la creación de nuevos e incluyentes diálogos y concertaciones entre una pluralidad de actores sociales, tradicionales y emergentes. Las mujeres figuran como parte de estos actores, sin embargo, su participación denota la deficiente calidad de nuestra democracia, a juzgar por la infrarrepresentación en los gobiernos locales: constituyen apenas el 10\% de las personas que se desempeñan como alcaldes (as); son minoría -en relación a los hombres- en instancias de toma de decisiones y de planificación del desarrollo a nivel local. No obstante, se observa paridad genérica en órganos de consulta / concertación. Se evidencia entonces que, a medida que asciende el poder, disminuye la participación femenina.

En las estructuras organizativas y administrativas de las Alcaldías, se presenta el fenómeno de la Segregación Ocupacional en sus dimensiones horizontal y vertical. La precariedad y la flexibilidad laboral, signos de la Globalización, afecta a las mujeres.

Las instituciones que le dan forma a la democracia local no parecen reconocer a las mujeres como ciudadanas activas; las homologan en sus intereses como "una masa inseparable" incapaz de producir individualidades: principal característica de los miembros de la polis. Las mujeres ejercen -todavía- la ciudadanía pasiva, pues no se han constituido en titulares de derechos y con poder de situar en agenda pública sus intereses.

A pesar de la creciente participación numérica de las mujeres en el ámbito local, los mecanismos de participación ciudadana institucionalizados no parecen orientar esfuerzos y recursos para que las mujeres como colectivo -con sus propios intereses, tanto prácticos como estratégicos- conozcan los instrumentos jurídicos y desarrollen la "agencia", es decir, el proceso que conduce al empoderamiento.

Hasta el momento, ni la proximidad a la población, ni los cambios en el perfil de los gobiernos locales, así como la revalorización de los mismos, han incidido de forma significativa a la histórica desigualdad de género, a juzgar por las formas en que participan en instancias ciudadanas de toma de decisiones y en el poder político local. Las políticas de Descentralización, ni las reformas a nivel municipal, han traído consigo cambios sustantivos en las brechas de género en general, y las del ámbito político en particular. La democracia local -en construcción- se torna deficiente y excluyente, pues tiene reductos. 
La rendición de cuentas tiene fuertes vínculos con el empoderamiento, en una relación de causa y efecto. Por medio de la rendición de cuentas las mujeres se empoderan, pues hacen uso de sus derechos sociales, civiles y políticos. A la vez es el resultado de que la sociedad las ha percibido como sujetos políticos, con la capacidad de pedir cuentas a la comunidad política de la que son parte.

Existen avances de la incorporación del enfoque de género a nivel local. Éstos son poco conocidos, incipientes, aislados y carecen de sostenibilidad. Los logros alcanzados ha sido por la influencia de "los signos" de la Descentralización (la participación ciudadana y la necesidad de legitimación de los gobiernos); la movilización del movimiento de mujeres y del movimiento feminista a nivel nacional y local; la fuerza que han acumulado los organismos y organizaciones de mujeres; la influencia de la Cooperación Internacional; los avances en materia jurídica (normas, convenciones internacionales, leyes) relativas a los derechos humanos de las mujeres y los retos propuestos por los Objetivos de desarrollo del Milenio.

La Descentralización representa un desafío para los gobiernos locales cuando se le interroga desde la perspectiva de género, ya que remite justamente al reto sin parangón, como es la construcción de la Democracia.

La descentralización representa una oportunidad para propiciar cambios históricos relativos a la erradicación de mecanismos que perpetúan la desigualdad de género. Las mujeres deben apropiarse de los discursos democráticos y de los mecanismos de participación ciudadana. Sin embargo, se requiere del desarrollo de estudios a profundidad utilizando el marco analítico de la teoría de género, para desentrañar la manera en que paradójicamente la Descentralización podría conllevar a perpetuar la desigualdad histórica de las mujeres.

\section{Notas}

1. Considerada -según el enfoque del Banco Mundial- como la forma más débil de Descentralización, se reduce a un cambio de responsabilidades desde los funcionarios del gobierno central, en la ciudad capital, hacia aquellos que trabajan en regiones, provincias o distritos.

2 Los objetivos del milenio a ser logrados a más tardar en el año 2015, fueron el resultado de la Cumbre del Milenio auspiciada por Naciones Unidas en septiembre del 2000, con la participación de 189 Estados.

3. Las críticas se centran en la falta de transversalidad del género en el conjunto de los Objetivos de Desarrollo del Milenio, a pesar de que fue precisamente Naciones Unidas quien impulsó desde los años 80 la incorporación de la perspectiva de género en todas las políticas.

4. Aristóteles se refería a las mujeres como esclavos naturales. Éstas no eran parte de la polis (ciudades griegas), pues según su pensamiento, la naturaleza las había hecho inferiores. Escribe en "La Política": "Lo masculino está por naturaleza más dotado para mandar y dirigir que la mujer".

5. En Nicaragua, Renzi y Agurto (1992) analizan el impacto del ajuste estructural en las mujeres y la forma en que ellas y sus familias enfrentan la crisis económica.

6. Véase Castillo (2006).

7. Ver Espinoza (2004).

8. Ver: Centeno (2001).

9. La ley de participación ciudadana en el artículo 54 establece que el CDM podrá ser convocado por el Concejo Municipal, a través del alcalde o del secretario del Concejo Municipal, sin detrimento de sus relaciones con otras organizaciones de la sociedad civil.

10. Véase Ortner (1979). 
11. Se refiere a la asociación de "lo masculino" al ámbito público y "lo femenino" al ámbito privado. Lo primero, mediante el orden social de género, tiene mayor valoración social. Esta división en el ámbito de las estructuras sociales y políticas data desde la llustración y ha sido justificada por contractualistas como J.J Rosseau y Kant etc.Véase: Amorós (2000), Cavana (2000), Jiménez (2000).

12. Ver: Tendencias del Asociacionismo municipal en Centroamérica, el caso de Nicaragua, FUNDAUNGO, CASC-UCA (2004).

13. El plan de desarrollo municipal es la conclusión de la planificación estratégica y ésta es a su vez, la primera fase del sistema de planificación municipal. Aquí se identifica y define de manera concertada con los actores locales: la visión de desarrollo, líneas estratégicas, programas, proyectos y acciones para el desarrollo del municipio. En esta fase se definen acuerdos y compromisos para llevar a cabo acciones concretas, asegurando así que las capacidades y los recursos de todos los actores locales se utilicen de manera racional y equitativa (INIFOM. AMUNIC, 2004:6)

14. Esta información se desprende de la experiencia de Ana Isabel Espinoza como investigadora del "Mapeo institucional de Género", realizado para UNIFEM-PNUD, Nicaragua, 2005, sin editar.

15. García (2003) define "Género en el Mainstream" como una propuesta conceptual, metodológica y técnica para el logro de la Igualdad. Posee una importante influencia y penetración como una estrategia global o sectorial de intervención, orientada al logro de la igualdad de género en instituciones, organizaciones o contextos sociales, en la acción de las administraciones nacionales y locales públicas, incluso en organizaciones privadas, así como en los organismos de cooperación multilaterales. El análisis de género que esta estrategia demanda, parte de la premisa de que políticas públicas no son neutrales y por tanto tienen impactos diferenciales para los hombres y las mujeres.

16. La doble jornada es un término acuñado por Caroline Mosser (1995) para evidenciar la sobrecarga de trabajo de las mujeres: roles domésticos (no remunerados) y roles productivos (remunerados). Con el avance teórico y metodológico de los temas de género, se añadió el rol político / comunitario (no remunerado).

17. Como es el caso de la transversalización del enfoque de género en la Policía Nacional, experiencia calificada como sin parangón en Latinoamérica dada la dificultad de introducir cambios de mentalidades y de prácticas en una institución concebida -desde la ideología patriarcal- como de naturaleza masculina.

18. El "poder desde dentro o poder interior" es definido por Magdalena León (1997) como la base desde la cual construir a partir de sí misma. Es el poder que surge del mismo ser y no es dado o regalado. A partir de este tipo de poder se construye la autonomía de las mujeres.

19. Los desafíos que genera el tema de la rendición de cuentas para los municipios nicaragüenses son mayúsculos. Las pocas experiencias que han tenido cabida se expresan en los cabildos. En estos espacios los gobiernos locales -según la ley de municipios- tienen que consensuar con la población el presupuesto municipal y enterar el uso de los fondos públicos.

\section{Referencias bibliográficas}

-AMORÓS, A. (2000). "División sexual del trabajo”. En: Amorós, C. 10 palabras clave sobre Mujer. Navarra: Verbo Divino.

-AMORÓS, C. (1989). “Mujeres, feminismo y poder”. Madrid: Forum de Política Feminista. -AMORÓS, C. (1985) "Espacio de los iguales, espacio de las idénticas. Notas sobre poder y principio de individuación, Arbor, nov/dic.

-AMUNIC - INIFOM (2004). Sistema de Planificación Municipal, Guía Técnica. Managua: PRODEMU-DANIDA.

-ARANA, L. y CENTENO, R. (2003). Estructuras de poder y prestigio relacionadas con el Género en la Universidad Centroamericana. Managua: UCA.

-ASTELARRA, J. (1990). Participación política de las mujeres. Madrid: CIS.

-BACKHAUS, A. (2003). Modernización del Estado, cambio institucional y Género.

Managua: Proyecto de Promoción de Políticas de Género, GTZ-Gobierno de Nicaragua.

-BELLI y LÓPEZ (2005). Análisis de la articulación de los instrumentos de planificación municipal y departamental con el Plan nacional de desarrollo. Managua: AMUNIC/ PNUD.

-BID- INIFOM (2004). Diagnóstico Nacional sobre Género en el Desarrollo Municipal. -BRITOS, A. (2000). La institucionalización del enfoque de género en el desarrollo local. 
Latin American Studies Associations.

-CALHOUN C et.al (2000) Sociología, Mc Graw Hill, Madrid

-CASTILLO, M. (2006). Informe del diagnóstico nacional sobre el estado de organización de los CDMs. Nicaragua: Red Nicaragüense por la Democracia y el Desarrollo Local.

-CENTENO, R. (2004). Tendencias del Asociacionismo municipal en Centroamérica, caso de Nicaragua. Managua: FUNDAUNGO, CASC-UCA.

-CENTENO, R. (2001). "Algunas reflexiones sobre desarrollo, medio ambiente y género en Nicaragua”, Encuentro, No. 56, 126-133, Managua.

-COBO, R (2000). “Género”. En: Amorós C. 10 palabras clave sobre Mujer. Navarra: Verbo Divino.

-CONNELL, R. (1987). Gender and Power. Society, the Person and Sexual Politics. Cambridge: Polity Press.

-COS-MONTIEL, F. (2006). La Descentralización y los Derechos Humanos de las Mujeres en América Latina y el Caribe, Documento conceptual para el concurso 2005

de investigaciones de la unidad de Género del IDRC.

-ESPINOZA, I. (2004). Perfil de Género de la Economía nicaragüense en el nuevo contexto de la apertura comercial. Managua: UNIFEM.

-GARCÍA A. (2003). Género y ciudadanía: análisis de desafíos para el Estado y el desarrollo local. VIII Congreso Internacional del CLAD sobre la Reforma del Estado y de la Administración Pública, Panamá, octubre 2003.

-GARCÍA, E. (2006). El espejismo de la igualdad: el peso de las mujeres y de lo femenino en las iniciativas de cambio institucional. Caracas, sin editar.

-GARCÍA, E. (2003). Hacia la institucionalización del enfoque de Género en las políticas públicas. Caracas: Fundación Friedrich Ebert.

-GAVENTA, J. (2004). Hacia una gestión participativa de los asuntos públicos locales: seis propuestas para la discusión Instituto de estudios para el desarrollo.

-GOETZ, A. (1995). "Institutionalizing womens interest and accountability to womens and developments projects”. IDS Bulletin. Vol. 26 No. 3.

-GOETZ, A. (1995). The Politics of Integrating Gender to state Development

Processes. Trends, Opportunities and Constrains in Bangladesh, Chile, Jamaica,

Mali, Moroco and Uganda. New York: UNDP, Occasional paper.

-GUZMÁN, V. (2003). Gobernabilidad democrática y género, una articulación

Posible. Santiago de Chile: CEPAL, serie Mujer y desarrollo.

-INSTITUTODEFOMENTOMUNICIPAL,INIFOM(2002).Manualdelprocesopresupuestario y los cabildos municipales. Managua: Proyecto de transmisión de Gobiernos Locales.

-JIMÉNEZ, A. (2000). "Igualdad”. En: Amorós C., 10 palabras clave sobre

Mujer. Navarra: Verbo Divino.

-JUSIDMAN, C. (2004). Participación ciudadana y equidad de género en la construcción de agendas locales [en línea]. Foro Género, Gobernabilidad y Agendas locales, 6 de agosto del 2004. Disponible en Internet: www.undp.org.mx.

-KABEER, N. (2003). Gender Mainstreaming in Poverty Erradication and the Millenium Development Goals. Londres: Commonwealth Secretariat.

-KABEER, N. (1998). Realidades trastocadas. Las jerarquías de género en el pensamiento del desarrollo. México: Paidós.

-KABEER, N. (1994) Reversed realities, Gender Hierarchies in Development Thought. Londres: Verso, New Cork. 
-LA GACETA DIARIO OFICIAL No. 162, 26 de agosto 1997. Reformas e incorporaciones a la Ley No.40, “Ley de municipios”.

-LA GACETA DIARIO OFICIAL No. 241 del 19 de diciembre 2003, Ley No. 475, Ley de Participación ciudadana.

-LEÓN, M. (1997). “El empoderamiento en la teoría y práctica del feminismo”. En: León, M. Poder y empoderamiento de las mujere., Santa Fé de Bogotá: Tercer Mundo Editores.

-MASSOLO, A. (2005). "Notas sobre la gobernabilidad local, la participación de las mujeres y la equidad de género en la agenda de los gobiernos municipales”. Participación en Foro: Género, gobernabilidad y agendas locales. México: PNUD.

-MASSOLO A. (2002). Políticas públicas locales de equidad de género, una innovación de la gestión municipal [en línea]. Disponible en Internet: www.redmujer.org.ar.

-MASSOLO A. (2000). "La incursión de las mujeres en los procesos de descentralización, en Mujer, participación y desarrollo. Quito: CORDES.

-MONTENEGRO, S. y CUADRA, E. (2003). La Descentralización en Nicaragua:

Diagnóstico del proceso. Managua: Centro de investigaciones de la Comunicación. -MOSER, C. (1995).Planificación de género y desarrollo. Teoría , práctica y capacitación. Lima: Editorial Red entre mujeres, Flora Tristán.

-MURGUIALDAY, C. (2006). "El largo camino hacia la equidad de género" revista Pueblos, $\mathrm{N}^{\circ} 20$, pp. 34-36 .

-ORTNER, S. (1979). “¿Es la mujer con respecto al hombre lo que la naturaleza con respecto a la cultura?”. En Harris y Young, Antropología y Feminismo. Barcelona: Anagrama.

-RAWLS, J. (1971). Teoría de la Justicia.

-SCOOT, J. (1996). “El género: una categoría útil para el análisis histórico”. En: Lamas, M. El género: la construcción cultural de la diferencia sexual. México: Programa Universitario de Estudios de Género, UNAM, Miguel Ángel Porrúa.

-VALCÁRCEL, A (1997). La Política de las mujeres. Madrid: Ediciones Cátedra.

-WEBER, M. (1964). Economía y sociedad: esbozo de sociología comprensiva. México:

Fondo de Cultura Económica, segunda edición.

\section{SIGLAS}

AMUNIC (Asociación de municipios de Nicaragua)

BID (Banco Interamericano de desarrollo)

BM (Banco mundial)

CT (Comité Territorial)

CDM (Comité de desarrollo municipal)

GTZ (Agencia de cooperación técnica alemana)

IDR (Instituto de desarrollo rural), CDM.

MAGFOR (Ministerio de agricultura y forestal)

MARENA (Ministerio del ambiente y recursos naturales)

MINSA (Ministerio de salud)

MECD (Ministerio de educación, cultura y deportes)

PDM (Planes de Desarrollo Municipal)

PDD (Planes de desarrollo departamental)

PIMM (Plan de Inversión Municipal Multianual

UNIFEM (Fondo de desarrollo de las Naciones unidad para la mujer) 